\title{
A Terror Management Analysis of Perceived Purpose: The Effects of Mor- tality Salience on Attributions for Occurrences
}

\author{
Jonathan F. Bassett* and Stacey B. Going
}

Department of Psychological Science Lander University, 320 Stanley Ave, Greenwood, SC 29649, USA

\begin{abstract}
The current paper presents the results from two studies designed to test the hypothesis, derived from Terror Management Theory, that reminders of death would increase the need to perceive telos or purpose behind occurrences in the social world. In Study 1, mortality salience increased university students' perception that the events described in vignettes happened for a reason or purpose but only when the consequences were life altering and negative. In Study 2 , mortality salience decreased university students' perception that life-altering occurrences that affected other people were due to luck or chance. The results of these studies are interpreted as evidence that the need to believe that everything happens for a reason is motivated by a desire to manage existential anxiety.
\end{abstract}

Keywords: Terror Management Theory, mortality salience, teleological beliefs, attributions.

A Terror Management Analysis of Perceived Purpose: The Effects of Mortality Salience on Attributions for Occurrences

"I believe that everything happens for a reason. People change so that you can learn to let go, things go wrong so that you appreciate them when they're right, you believe lies so you eventually learn to trust no one but yourself, and sometimes good things fall apart so better things can fall together."

\section{Marilyn Monroe}

The idea that everything happens for a reason is a popular sentiment open to multiple interpretations. In one sense it could be taken to mean that the universe is not random or chaotic but rather governed by causal laws that can be discerned through observation. This premise is the central underpinning of the empirical epistemology that forms the basis for scientific investigation. However, it could also be taken to mean something like divine providence, such that the universe is governed by a beneficent force that adheres to humans principles of justice. The authors of the present paper argue that maintaining a belief that the world is not only orderly and predictable but also beneficent and fair is essential to human psychological equanimity. We further argue that the human motive to perceive purpose in the social world serves a terror management function by mitigating existential anxiety.

\section{MAKING SENSE OF THE WORLD}

Human beings are meaning-creating creatures that develop causal models of the relation between self and the

*Address correspondence to this author at the Department of Psychological Science Lander University, 320 Stanley Ave, Greenwood, SC 29649, USA;

Tel: (864) 388-8740; Fax: (864) 388-8732; E-mail: jbassett@lander.edu external world and impose those models on experience in order to interpret the world in an orderly and stable way [1$3]$. The ability to create meaningful mental representations of the constant stream of sensory information is essential for the sense of control and predictability required to pursue goal-directed behavior.

Perhaps the most eloquent proponent of the human need for meaning was Viktor Fankl, who in his experience as a prisoner in a Nazi concentration camp, observed that the prisoners who were able to survive were those who could find some meaning in their suffering and maintain some hope for a future life [1]. Frankl used this experience as the basis for developing an approach to psychotherapy know as logotherapy, in which he rejected the Freudian claim that people were motivated by the desire for pleasure in favor of the claim that "the striving to find a meaning in one's life is the primary motivational force" (p. 154).

Later theorists have followed in the tradition of privileging meaning over other human needs. For example, Baumeister argued that humans share basic physiological needs with all other animals and share needs for power and belongingness with other social animals. The need for meaning is unique to humans, however, as we are the only cultural animals. In fact, Baumeister posited that meaning is even more important than happiness in determining life-satisfaction, as people can delay hedonic satisfactions and endure suffering in the pursuit of meaningful goals [2]. Similarly, according to the meaning maintenance model [3], the primary human psychological motive is to perceive the world as meaningful. Threats in the domains of uncertainty, damaged self-esteem, or interpersonal rejection undermine perceived meaning, because they violate expectations about the social world derived from mental models and consequently people respond to these threats with compensatory efforts to re-establish meaning. 
From one perspective, the human quest for meaning is primarily a rational one in which individuals act like amateur scientists weighing various sources of information with the goal of making the most accurate decision. Kelly's covariation model is a prime example of this approach. In this model, people make attributions to an actor, a target, or situational factors by examining information about consistency, consensus, and distinctiveness [4]. However, people may not always be motivated to seek out sufficient information to make correct decisions. From the social cognition perspective, people are cognitive misers and will trade accuracy for speed by relying on heuristics [5]. People are motivated by a need to perceive the world accurately, but due to the overwhelming amount of information about the social world available through the senses, they must take shortcuts and rely on schemas to simplify the social world.

However, social psychologists have recognized that attributions about social behavior are not always produced purely out of a desire for accuracy but rather suffer from motivational biases. Kunda articulated a motivated social cognition perspective in which people frequently evaluate evidence in order to confirm pre-existing beliefs [6]. People are not always rational scientists following the evidence to its natural conclusion but rather selectively attend to, distort, and manipulate evidence to protect fundamental assumptions about the world, the violation of which would produce psychological distress.

Lerner identified one such motive as the need to believe in a just world in which good things happen to good people and bad things happen to bad people. More specifically, he argued that the aversion to witnessing the suffering of innocent people leads to a biased attributional process, in which people are motivated to blame the victim of negative life events [7]. Similarly, Janoff-Bulman argued that our perception is influenced by an assumptive worldview characterized by trust in the benevolence of other people, the meaningfulness of existence, and the worthiness of our self. Traumatic events that shatter these assumptions severely undermine psychological well-being [8].

Although a variety of motivational biases may influence people's perceptions of the social and natural world, these motives may not be ends in themselves but may be a means of accomplishing the broader goal of mitigating existential anxiety. According to one perspective known as Terror Management Theory [9], the desire to perceive the self as a worthy contributor to a fair and meaningful world operates in the services of the more overarching goal of attenuating the potentially debilitating anxiety stemming from the uniquely human awareness of personal mortality.

\section{TERROR MANAGEMENT THEORY}

Terror Management Theory (TMT) is based on the central premise that the uniquely human awareness of death presents a potentially debilitating source of anxiety that must be managed [9]. According to TMT, individually internalized but consensually validated social fictions known as cultural worldviews serve as a psychological buffer against death anxiety by delineating the prescribed standards of behavior that allow adherents to believe that they are making a valuable contribution to some meaningful and enduring pro- ject. Cultural worldviews serve as psychological shields against the anxiety derived from the human awareness of the universality of death and vulnerability to myriad potentially lethal threats by allowing individuals to perceive the world as an orderly and manageable place where death by accident or disease can be avoided through proper vigilance. Cultural worldviews also serve to mitigate the existential anxiety derived from the awareness of the inevitability of death and fears of personal extinction by offering hope for some means of literal or symbolic immortality in which an individual's identity is defined as more valuable and enduring than a corporeal, corruptible, and creaturely container.

Empirical support for the terror management function of culture comes from findings that experimentally-induced thoughts of death increased discomfort with using valued national and religious symbols in inappropriate ways [10], led to greater derogation of those who criticized one's country [11], and increased liking for attitudinally, politically, and religiously similar others [12]. In addition, threatening national values and challenging religious beliefs increased the accessibility of death-related thoughts leaving people vulnerable to the potential experience of existential anxiety [13]. The effects of mortality salience on cultural worldview defense are not attributable to general negative emotions and similar reactions are not generated in response to priming other aversive thoughts [14]. Further, both giving participants a placebo that purportedly blocks anxiety [15] and providing participants with bogus scientific evidence supposedly supporting the existence of literal immortality [16] have been shown to reduce defensive reactions in response to reminders of death, thereby suggesting that these defenses are enacted specifically as a way to ward off death anxiety.

\section{TMT AND ATTRIBUTIONS}

If motivational biases to perceive the world as fair and beneficent can influence causal attributions and these motivational biases operate to maintain the integrity of a cultural worldview that buffers the self from existential anxiety, then it follows that reminders of death should influence the attribution process. Consistent with this reasoning, previous studies have demonstrated how experimentally-induced thoughts of death can influence attributions. For example, Mikulincer and Florian demonstrated that mortality salience intensified the self-serving bias in which internal, global, and stable attributions were given for personal successes and external, specific, and unstable attributions were given for personal failures [17].

In addition, mortality salience led to increased nationalistic bias in assigning blame to the maker of a car involved in an accident [18]. Participants were presented with stories depicting a person who was injured in an automobile crash. The details of the case were the same except for whether the car was a foreign or domestic model. Compared to participants in the control condition, those in the mortality salience condition assigned more blame for the accident to the manufacturer of the foreign car than to the manufacturer of the domestic car. These findings support the role of terror management processes in attributions. Because self-esteem and cultural worldview serve a death-anxiety-buffering function, reminders of death motivates defensive attributions to en- 
hance the perception that the self is valuable and that one's in-group is superior to out-groups.

Similarly, Hirschberger argued that people would engage in a rational, evidenced-based attribution process when existential threat was not salient but that when people felt vulnerable, such as when reminded of their mortality, they would engage in a defensive attribution process, such as blaming the victim to protect the belief in a just world [19]. In two studies, he showed that mortality salience reduced the normal compassionate response to severely injured accident victims. Compared to participants in the control conditions, those who had been reminded of death assigned more blame to accident victims but only when those victims were severely injured. Further, the results of a third study showed that the effects of mortality salience were driven by a defensive motive to protect the belief in a just world. When the injured person depicted in the vignette was clearly responsible for the accident by driving recklessly, mortality salience had no effects on attributions of blame to the victim. However, mortality salience did increase attribution of blame to innocent victims when they were severely injured.

The studies described above offer converging evidence that the need to manage existential terror can motivate biased attributions to maintain the assumptions about the value of the self and fairness of the world that form the basis of the death-anxiety-buffer composed of self-esteem and cultural worldview. There may be, however, an additional motivational aspect of the death anxiety buffer that biases attributions- namely the need to perceive purpose in the world. It would be difficult to maintain beliefs about the meaningfulness and value of existence without also being convinced that everything happens for a reason.

\section{THE NEED TO PERCEIVE PURPOSE}

Davis, Juhl, and Routledge examined the need to perceive purpose in the natural world [20]. Specifically, they focused on teleological beliefs that involve explaining natural phenomenon in terms of progressing toward some ultimate goal. Teleological beliefs are not rationally warranted, because from a scientific perspective the natural world is not assumed to operate in the pursuit of some goal. These authors posited that teleological beliefs stem from a motivational bias to ameliorate existential anxiety because unless the natural world is imbued with purpose, it is difficult to create a meaningful and significant human role in the world that would afford the means to self-esteem and literal or symbolic immortality.

Davis et al. reported evidence from three studies supporting the terror management function of perceiving purpose [20]. In Study 1, providing arguments supporting teleological beliefs reduced the accessibility of death-related thoughts. In study 2 , subtle reminders of personal death increased people's general belief that everything happens for a reason. In Study 3, mortality salience led to an increased agreement with specific scientifically unwarranted teleological statements about nature such as "bees carry pollen to help plants grow." The results of these three studies led Davis et al. to conclude that perceiving purpose is an important function of cultural worldview that facilitates the management of existential terror.

The present research extended the terror management analysis of purpose by examining the causal attributions for circumstantial events that affect the lives of other people. If perceived purpose assuages death anxiety, then priming individuals to think about their mortality should increase the tendency to see purpose or design behind why things happen to other people. This tendency should be especially strong when the events have life-altering and negative consequences in the lives of other people, because it is under these conditions that one would feel most vulnerable to similar outcomes and most need to validate the assumption of purpose, which is an important death-anxiety-buffering property of cultural worldview.

\section{Study 1}

The goal of Study 1 was to demonstrate the terror management function of perceived purpose by showing that mortality salience increased the need to perceive occurrences in the social world as happening for a reason. The current research extends previous TMT research that has focused on teleological beliefs about the natural world and endorsements of general statements about perceived purpose [20], by examining causal attributions for specific social phenomena in the form of occurrences that happened to other people. The present study differs from previous TMT research on blaming victims who were injured by accident or attack [19] in that the more general need to perceive purpose behind an array of outcomes with social, health, and financial consequences was examined. Participants were randomly assigned to a mortality salience or control condition prior to reading vignettes depicting positive or negative and life-altering or not life-altering events that happened to other people. These events were occurrences because the outcomes were not causally connected to the actions of the people involved but rather happened due to forces outside their control. It was hypothesized that participants in the mortality salience condition would view the occurrences as more likely happening for some purpose than would participants in the control condition.

\section{METHOD}

\section{Participants}

Participants were 72 students enrolled in introductory psychology classes. Students received partial credit towards the fulfillment of a class research participation requirement. All participants were treated in accordance with the ethical principles and guidelines of the American Psychological Association [21]. The responses from 3 participants were dropped, because they failed to answer the mortality salience induction questions. Due to a copying error, demographic information was not obtained for 42 of the 69 remaining participants. Of the participants for whom demographic information was obtained, 10 were men and 27 were women and they ranged in age from $18-22$ years $(M=18.96, S D=1.22)$. These demographics are characteristic of the student body at the institution where the research was conducted and are likely representative of the entire sample. 


\section{Materials and Procedure}

Participants arrived in groups of 5-15 to a psychology laboratory to participate in what they were told was a study about personality and how people explain why things happen. After signing informed consent forms, participants completed the 10-item Personality Inventory [22] as a filler task to give credibility to the purported interest in personality. Following a procedure described by Hirschberger and Ein-Dor, participants were randomly assigned to write about their own death or taking a difficult exam [23]. Participants in the mortality salience condition wrote responses to two open-ended questions about their own death, whereas participants in the control condition wrote responses to two parallel questions about taking a difficult exam.

Following the mortality salience or exam prime, participants completed the Positive and Negative Affect Schedule (PANAS) as a measure of current mood [24]. This measure is typically included in mortality salience studies to rule out the possibility that the effects of the manipulation are due to general negative affect. Following the procedure described by Lyall and Thorsteinsson [25], a delay was created between the mortality salience induction and the dependent measure by having participants respond to 10 items about their activity level taken from the International Personality Item Pool (IPIP) available at http://ipip.ori.org/ [26]. This distracter task was included because previous research has found that mortality salience elicits the greatest effect on symbolic defenses when thoughts of death are no longer the focus of conscious attention [27].

All participants then read four vignettes (see Appendix) developed and used in previous research on attributions by Lupfer, Tolliver, and Jackson [28]. These vignettes described occurrences with either positive or negative and either lifealtering or not life-altering consequences. Lupfer et al. reported the results of pilot testing supporting the fact that participants viewed the vignettes in the expected ways along the dimensions of valence and impact. When they had participants rate how positive or negative the vignettes were, on a scale from 1 (very negative) to 7 (very positive), positive vignettes received valence ratings significantly above the scale midpoint, whereas negative vignettes received valence ratings significantly below the scale midpoint. When they had participants rate how much the outcome changed the central character's life, on a scale from 1 (not much change) to 7 (completely change), life-altering vignettes received impact ratings significantly above the scale midpoint, whereas not life-altering vignettes received impact ratings significantly below the scale midpoint [28].

In the current study, for each vignette, participants rated how true they thought two statements were on a 7-point scale anchored at 1 (absolutely not true) and 7 (absolutely true). Specifically, participants rated the extent to which they thought the events in the vignette "happened as part of a grand purpose even if those involved don't realize it" and "there was no rhyme or reason to why it happened it just happened." This second item was reverse scored and an average score was created for each vignette such that higher scores indicated greater teleological belief that there was a purpose behind why things happen.

\section{RESULTS}

A multivariate analysis of variance was conducted with condition (mortality salience/control) as the independent variable and the rated purpose for each of the four occurrences as the dependent variables. There was a marginal multivariate effect for condition, $F(4,64)=2.18, p=.082$, $\eta_{\mathrm{p}}{ }^{2}=.120$. As can be seen in Table 1, participants in the mortality salience condition perceived nominally more telos/purpose behind why all four occurrences happened than did participants in the control condition. However, separate independent sample $t$ tests revealed that this difference only reached statistical significance for the vignette depicting an occurrence with negative and life-altering consequences.

\section{DISCUSSION}

The results of Study 1 were consistent with the hypothesis that believing everything happens for a reason serves a terror management function. Participants in the mortality salience condition were more likely to view negative and life-altering occurrences as happening for a reason and purpose than were participants in the control condition. This finding extends previous work on the terror management function of teleological beliefs about nature and the world in general [20] to beliefs about specific events in the social world. The fact that the effects of mortality salience in the present study were limited to occurrences with negative and important consequences is consistent with a terror management perspective, because it is under these circumstances that people would feel most vulnerable to existential threat.

When we observe bad things happening to others that negatively affect their lives in important ways, it can chal-

Table 1. The Effects of Mortality Salience on Perceived Purpose

\begin{tabular}{|c|c|c|c|c|}
\hline & Mortality Salience & Control & & \\
\hline Positive/ life-altering & $5.37(1.82)$ & $4.94(1.94)$ & 0.95 & .346 \\
\hline Positive/ not life-altering & $4.79(1.85)$ & $4.50(1.67)$ & 0.67 & .503 \\
\hline Negative/ not life-altering & $5.15(1.83)$ & $4.78(1.66)$ & 0.89 & .373 \\
\hline
\end{tabular}


lenge the assumptions of our worldview about the predictability, fairness, and meaningfulness of the forces governing the universe. If the wellbeing of others can be threatened by forces that are unjust, unpredictable, or indifferent to human concerns, then the implications are that one's own wellbeing is precarious and equally vulnerable to the same forces. Previous research has shown that reminders of death can motivate blaming the victims of negative events as a way to abate existential anxiety [19]. The findings of the current study build on this tradition by documenting that existential threat can also motivate the perception of purpose behind why bad things happen to others. If the discomfort aroused by witnessing the undeserved suffering of innocent people cannot be made more palatable by blaming the victim, perhaps it can be abated by perceiving some purpose behind the events that makes them redemptive or necessary as part of a cosmic plan.

Although Study 1, provided initial evidence for a terror management function of perceived purpose, it was not possible to rule out order effects because the vignettes were not counterbalanced. A second study was conducted to improve upon this methodological issue, as well as to explore perceptions of purpose in a more nuanced way and to examine the potential moderating role of individual differences.

\section{Study 2}

The goal of Study 2 was to replicate conceptually the effect of mortality salience on the perception of purpose behind occurrences using a slightly different measure. Specifically, we wanted to examine the hypotheses that reminders of death would decrease perceptions that things happen randomly due to chance and increase perceptions that things happen as part of a divine plan. The former would be important in maintaining the belief that the world is orderly and predictable and the latter would be important in maintaining the belief that the world is governed by a beneficent force that is concerned with human well-being. Study 2, also examined defensive theology and personal need for structure as individual difference variables that might potentially moderate the effects of mortality salience on attributions for the causes of occurrences to God and chance respectively.

Davis et al. [20] suggested that the traditional Christian worldview ameliorates existential anxiety by allowing adherents to believe that "since God designed the world and humans for a purpose, life events that seem chaotic or random must be part of a grander plan or vision" (p. 99). The soothing effect of belief in divine purpose was beautifully articulated in a deathbed interview given by Ernest Becker (the cultural anthropologist whose work formed the foundation for Terror Management Theory). When asked about his imminent death from cancer, Becker [29] claimed that when confronting their mortality people can find solace in "the fact of the tremendous creative energies of the cosmos that are using us for some purpose we don't know. To be used for divine purposes, however we may be misused; this is the thing that consoles" (p. 226). This quote illustrates the desire to believe that there is some beneficent plan governing the universe that makes suffering tolerable because it happens for a reason as part of something that is bigger and more meaningful than the individual.
Previous research has shown that attributions to God became more prevalent than attributions to the human agency of the actors or the influence of other people when the events were occurrences (in which the target seemingly had little control over the outcomes) than when the events were actions (in which the target seemingly had control over the outcomes) and that this effect was most pronounced when the consequences were life-altering and positive [28]. People seem most likely to evoke God as involved in the world when good and important things happen. Perhaps this tendency reflects the view that God is too busy to meddle in trivial human affairs and only intervenes in important matters and also the desire to maintain the goodness of an all-loving God by not making him directly responsible for bad events.

In the current study, we expected that mortality salience would intensify the previously documented tendency for people to attribute important and positive events to God. However, we also examined the possibility that this effect would be moderated by individual differences in defensive theology. Beck [30] defined a defensive religious orientation as characterized by a rigid and unquestioned conviction in special divine protection, insight, and destiny, which allows for the maintenance of positive affect and the avoidance of existential anxieties related to death and meaninglessness but at the cost of less tolerance of those with different beliefs. Beck [31] developed the Defensive Theology Scale (DTS) to measure individual differences in the extent to which people held defensive religious orientations. He further demonstrated that scores on the DTS moderated the effects of mortality salience on cultural worldview defense, as only those participants with defensive religious orientations responded to reminders of death by derogating people with disparate religious beliefs. In the present study, we hypothesized that the tendency to attribute occurrences to God in response to mortality salience might be especially strong for participants high on DTS.

In addition to looking at perceived purpose in terms of attributions to God, we also examined the phenomenon from the other direction in terms of attributions to luck or chance. We reasoned that if mortality salience increased the need to perceive purpose in the social world then this need would be evidenced by a decreased tendency to attribute luck or chance as the cause of occurrences. We also examined whether the effect of mortality salience on perceived purpose would be moderated by individual differences in personal need for structure (PNS). Neuberg and Newsom [32] developed the PNS scale to measure individual differences in the extent to which people are motivated to construct simple and well-ordered mental representations of experience in order to minimize ambiguity. Several previous studies have examined how PNS moderates the effects of mortality salience on attributions.

Previous research has shown that mortality salience increases aversion to meaninglessness and increases the desire for structure and organization of the world but only among those dispostionally high in PNS. For example, mortality salience decreased liking for non-representational art only among those high on PNS [33]. Similarly, PNS moderated the effects of death primes on defensive attributions that protected beliefs in fairness and beneficence [34]. Landau et al. 
reported that only among participants high in PNS were those in the mortality salience condition more likely to seek information that devalued the victim of a crime than those in the pain or uncertainty conditions. Further, only among those high in PNS did mortality salience increase the appeal of a causally dependent movie plot, in which a man's apartment burning down led to his meeting the woman of his dreams, over a movie plot containing the same two causally unrelated events [34]. However, not all mortality salience studies have found a moderating role of PNS. Davis et al. [20] reported no effect of individual differences in PNS on the tendency for mortality salience to increase participants' endorsement of teleological statements as satisfactory explanations of the natural world. Given the frequency with which PNS is examined in previous mortality salience studies, we thought it prudent to include it in the current study. However, given the discrepancies in the previous findings, we were uncertain as to whether PNS would moderate the effects of mortality salience on perceived purpose for occurrences in the social world.

In study 2 of the current paper, participants were randomly assigned to a mortality salience or control condition prior to reading the same vignettes used in Study 1. For each occurrence, participants rated the extent to which they thought luck, God, characteristics of the person affected, and characteristics of the situation or influence of other people were likely causes. TMT asserts that reminders of death should intensify the need to perceive the world as orderly and not chaotic, so we hypothesized that mortality salience would increase attributions to God and decrease attributions to luck. Because the events depicted in this study were not easily attributable to the fault of the people affected or to the actions of others, we did not expect mortality salience to influence attributions to these causes but rather included them to serve as controls, in order to rule out the possibility that mortality salience would increase attributions to any potential cause.

\section{METHOD}

\section{Participants}

Participants were 79 students enrolled in introductory psychology classes. Students received partial credit towards the fulfillment of a class research participation requirement. All participants were treated in accordance with the ethical principles and guidelines of the American Psychological Association [21]. The response from 1 participant was dropped because she failed to answer the mortality salience induction questions. Given the focus of the present research on attributions to God, the responses from 8 additional participants were dropped because they indicated that they did not believe in a theistic notion of God. Of the remaining 70 participants, 15 were men and 55 were women. Participants ranged in age from $18-24$ years $(M=18.97, S D=1.04)$.

\section{Materials and Procedure}

Participants arrived in groups of 5-15 to a psychology laboratory to participate in what they were told was a study about personality and how people explain why things happen. After signing informed consent forms, participants pro- vided demographic information including age, gender, race, and religious affiliation. Participants also answered questions about their belief in God, religious attendance, and the importance of religion in their lives.

Participants then completed the 10-item Personality Inventory [22] as a filler task to give credibility to the purported interest in personality. Next, participants completed the Personal Need for Structure Scale (PNS) and the Defensive Theology Scale (DTS). The PNS [32] requires participants to rate their agreement, on a 6-point scale, with 11 statements about the extent to which they like order, predictability, and certainty. The DTS [31] requires participants to rate their agreement, on a 7-point scale, with 22 statements about the extent to which God offers them special protection from misfortune, gives them special insight into how to act, answers even their most trivial prayers or requests, and has a plan and purpose for their lives that is the reason behind everything that happens to them.

Participants were then randomly assigned to a mortality salience or control condition using the same procedure described in Study 1. Following the mortality salience or exam prime, participants completed the same measure of mood and distracter task described in Study 1.

All participants then read the same four vignettes described in Study 1 [28]. However, in Study 2 the vignettes were presented in counterbalanced order. In Study 2, the participants also made different ratings in response to the vignettes. Specifically, for each vignette, participants rated, on a 6-point scale anchored at 1 (not at all a likely cause) to 6 (a very likely cause), the extent to which the events in the vignette were caused by "the actions of the person affected", "the situation or influence of other people", "chance or luck", "as part of God's master plan."

\section{RESULTS}

\section{Attributions as a Function of Mortality Salience and Type of Occurrence}

The first set of analyses was aimed at examining how mortality salience would affect the types of attributions people made for occurrences and whether this effect would differ depending on the valence and impact of those occurrences. Therefore, valence $\mathrm{x}$ impact $\mathrm{x}$ mortality salience ANOVAs were conducted separately for the four attributions participants rated (luck, God, characteristics of the person affected, and characteristics of the situation or influence of other people).

\section{Attributions to luck}

Participants' ratings of the extent to which the occurrences were caused by luck or chance were subjected to a 2 (positive/negative) × 2 (life-altering/not life-altering) × 2 (mortality salience/exam salience) ANOVA with the valence and the impact of the occurrences in the vignettes as a within subjects variables and the type of prime as between subjects variable. There was a main effect for valence, $F(1,68)=$ $71.18, p=.000, \eta_{\mathrm{p}}{ }^{2}=.511$, with participants rating occurrences with negative consequence $(M=2.74, S D=1.21)$ as less likely to have been caused by luck than occurrences with positive consequences $(M=4.18, S D=1.42)$. There was a main effect for condition, $F(1,68)=4.56, p=.036, \eta_{\mathrm{p}}{ }^{2}=$ 
.063 , with participants in the mortality salience condition rating the occurrences $(M=3.17, S D=1.09)$ as less likely to have been caused by luck than did participants in the control condition $(M=3.72, S D=1.09)$. However, this main effect was qualified by a Condition $\mathrm{x}$ Impact interaction effect, $F$ $(1,68)=7.24, p=.009, \eta_{\mathrm{p}}{ }^{2}=.096$ that is depicted in Fig. (1).

When evaluating occurrences with consequences that were not life-altering, attributions to luck made by participants in the mortality salience condition $(M=3.39$, $S D=$ 1.29) did not differ significantly from those made by participants in the control condition $(M=3.65, S D=1.30), t(69)=$ $0.82, p=.416$. In contrast, when evaluating occurrences with consequences that were life-altering, participants in the mortality salience condition viewed the events as less likely to have been caused by luck $(M=2.93, S D=1.12)$ than did participants in the control condition $(M=3.78, S D=1.00), t$ $(69)=3.39, p=.001$. As hypothesized, mortality salience decreased the perception that occurrences were due to luck. However, this effect emerged only when the occurrences had life-altering consequences.

\section{Attributions to God}

Participants' ratings of the extent to which the occurrences were caused by God were subjected to a 2 (positive/negative) x 2 (life-altering/not life-altering) x 2 (mortality salience/exam salience) ANOVA with the valence and the impact of the occurrences in the vignettes as within subjects variables and the type of prime as a between subjects variable. There was a main effect for valence, $F(1,68)=$ $11.61, p=.001, \eta_{\mathrm{p}}{ }^{2}=.146$, with participants rating occurrences with positive consequence $(M=4.81, S D=1.15)$ as more likely to have been caused by God than occurrences with negative consequences $(M=4.31, S D=1.35)$. There was no main effect for condition but there was a marginal Condition $\mathrm{x}$ Valence $\mathrm{x}$ Impact three-way interaction, $F$ (1, $68)=3.11, p=.082, \eta_{\mathrm{p}}{ }^{2}=.044$, as depicted in Fig. (2).

To interpret this three-way interaction, the simple effect of condition was examined separately for each of the four vignettes. There was a marginal effect of condition on attributions to God in the positive and life-altering vignette, $t$ $(68)=1.82, p=.073$. Participants in the mortality salience condition viewed the positive and life-altering occurrences as more likely to have been caused by God $(M=5.15, S D=$

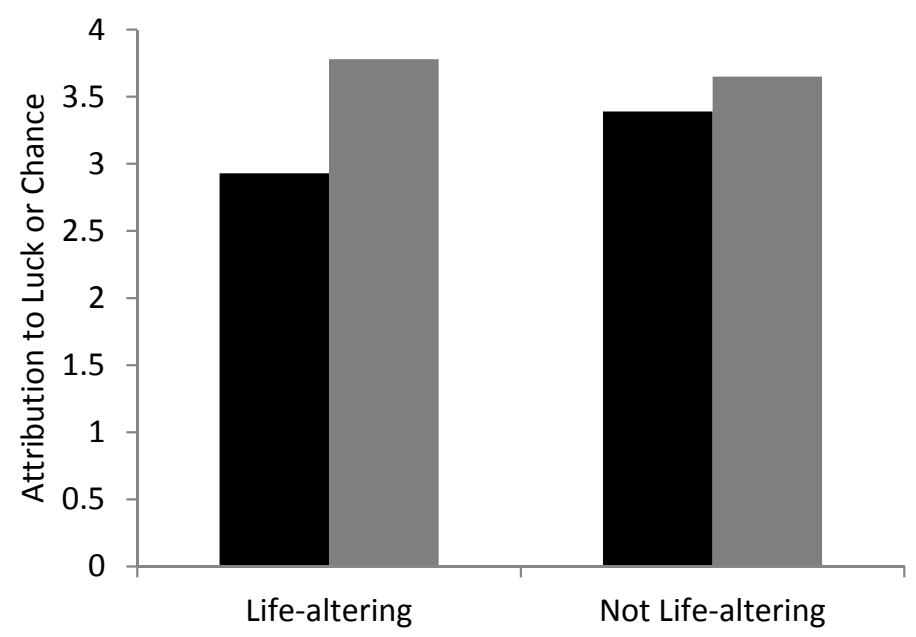

Mortality Salience

Control

Fig. (1). Attributions to luck or chance are presented as a function of mortality salience and the impact of the vignette. Mortality salience reduced attributions to luck or chance relative to control but only when the vignette had life-altering consequences.

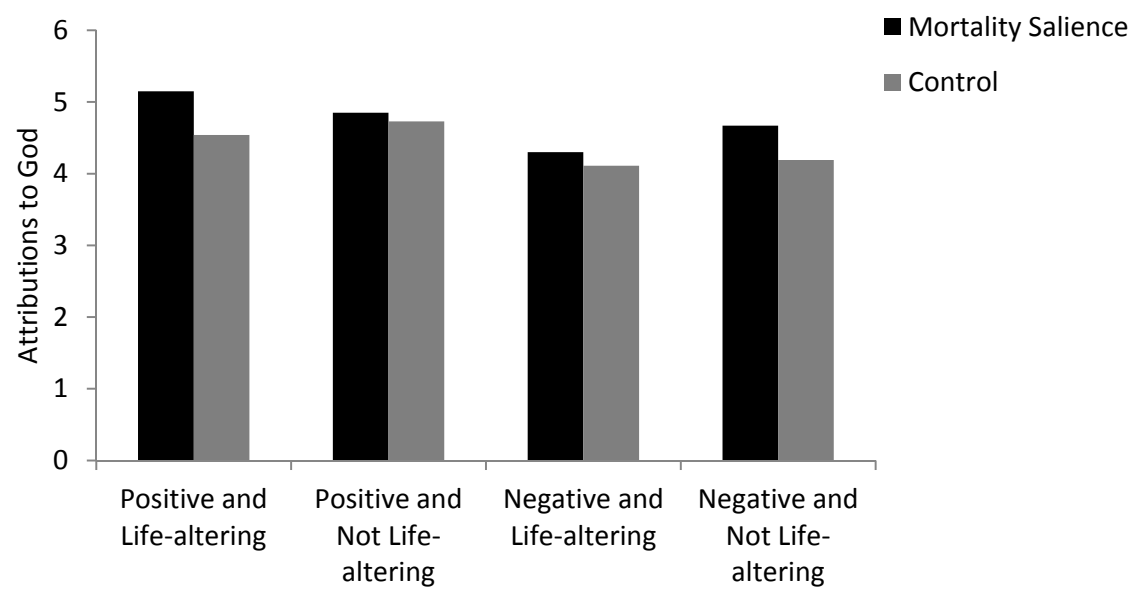

Fig. (2). Attributions to God are presented as a function of mortality salience, valence or vignette, and impact of vignette. Compared to control, mortality salience produced marginally greater attributions to God when the vignette had positive and life-altering consequences. Mortality salience had no effect on attributions to God for the other vignettes. 
1.18) than did participants in the control condition $(M=$ $4.54, S D=1.57)$. The simple effect of condition on attributions to God did not approach significance for any of the other three vignettes.

\section{Attributions to Characteristics of the Person Affected}

Participants' ratings of the extent to which the occurrences were due to characteristics of the person affected were subjected to a 2 (positive/negative) x 2 (life-altering/not lifealtering) $\times 2$ (mortality salience/exam salience) ANOVA with the valence and the impact of the occurrences in the vignettes as within subjects variables and the type of prime as a between subjects variable. There was no main effect for condition and no significant interactions with condition. There was a main effect for valence, $F(1,68)=17.93, p=$ $.000, \eta_{\mathrm{p}}{ }^{2}=.209$, and a main effect for impact, $F(1,68)=$ $12.79, p=.001, \eta_{\mathrm{p}}{ }^{2}=.158$. However, these main effects were qualified by a Valence $\mathrm{x}$ Condition interaction effect, $F$ $(1,68)=32.04, p=.000, \eta_{\mathrm{p}}{ }^{2}=.320$. When the occurrence had life-altering consequences, participants were more likely to view the persons affected as responsible for what happened when the outcomes were positive $(M=3.71, S D=$ $1.83)$ than when the outcomes were negative $(M=2.23, S D$ $=1.49), t(69)=6.62, p=.000$. In contrast, when the occurrence had consequences that were not life-altering, participants viewed the persons affected as equivalently responsible for what happened when the outcomes were positive $(M$ $=2.40, S D=1.48)$ and negative $(M=2.43, S D=1.57), t(69)$ $=0.19, p=.892$.

\section{Attributions to the Situation or Influence of Other People}

Participants' ratings of the extent to which the occurrences were due to the situation or influence of other people were subjected to a 2 (positive/negative) x 2 (life-altering/not life-altering) x 2 (mortality salience/exam salience) ANOVA with the valence and the impact of the occurrences in the vignettes as within subjects variable and the type of prime as a between subjects variable. There was a main effect for impact, $F(1,68)=14.49, p=.000, \eta_{\mathrm{p}}{ }^{2}=.176$, with participants viewing the situation or influence of other people as a more likely cause when the occurrences had consequences that were life-altering $(M=3.36, S D=1.47)$ than when the occurrences had consequences that were not life-altering $(M=$ $2.59, S D=1.32$ ). None of the other main or interaction effects approached statistical significance.

\section{Moderating Effects of Personality}

The next set of analyses examined the possibility that the effects of mortality salience on attributions might be moderated by individual differences on personality dimensions. Specifically, the author examined the possibility that personal need for structure might moderate the effect of mortality salience on attributions to luck and the possibility that defensive theology might moderate the effect of mortality salience on attributions to God.

\section{Personal Need for Structure, Mortality Salience, and At- tributions to Luck}

The effect of morality salience and personal need for structure on attributions to luck were tested using regression analysis. Separate regressions were performed for each of the four occurrences. Attribution to luck was the dependent variable. The categorical predictor variable condition (dummy coded as MS = 1 and control $=-1$ ) was entered in block 1 along with the centered continuous predictor variable personal need for structure. The multiplicative two-way interaction term was entered in block 2. In the analysis of attributions to luck, neither the main effect of PNS nor the Condition $\mathrm{x}$ PNS interaction effect reached statistical significance for any of the four occurrences. There was a marginal main effect for PNS for only 1 of the four occurrences. Greater PNS was associated with rating luck as a marginally less likely cause of occurrences with negative and not lifealtering consequences $(\mathrm{B}=-.491, \beta=-.205), t(69)=-1.71, p$ $=.092$.

\section{Defensive Theology, Mortality Salience, and Attributions to God}

The effect of morality salience and defensive theology on attributions to God were tested using regression analysis. Separate regressions were performed for each of the four occurrences. Attribution to God was the dependent variable. The categorical predictor variable condition (dummy coded as $\mathrm{MS}=1$ and control $=-1$ ) was entered in block 1 along with the centered continuous predictor variable personal need for structure. The multiplicative two-way interaction term was entered in block 2. The DTS x Condition interaction effect did not approach statistical significance for any of the four occurrences. There was a main effect of DTS on attributions to God for all four occurrences. Higher scores on the DTS were associated with a tendency to view God as a more likely cause for positive occurrences with consequences that were not life-altering $(\mathrm{B}=.033, \beta=.464), t(69)$ $=4.27, p=.000$, positive occurrences with consequences that were life-altering $(\mathrm{B}=.028, \beta=.346), t(69)=3.09, p=$ .003 , negative occurrences with consequences that were not life-altering $(\mathrm{B}=.033, \beta=.382), t(69)=3.42, p=.001$, and negative occurrences with consequences that were lifealtering $(\mathrm{B}=.029, \beta=.344), t(69)=-2.99, p=.004$.

\section{DISCUSSION}

The results of study 2 were consistent with the hypothesis that reminders of death would increase the tendency to perceive telos or purpose behind why things happen in the social world. Participants in the mortality salience condition were less likely to view occurrences as due to chance or luck than those in the control condition and this effect was most pronounced when the occurrences had life-altering consequence. This finding is consistent with previous evidence that mortality salience increases teleological beliefs about nature and the world in general [20] and extends this effect to specific events in the social world. When events substantially impact the lives of other people there seems to be an existential motive to view those events as purposeful rather than chaotic.

The findings of the present study also add to the literature on attributions to God. Consistent with previous research [28], participants in the current study were more likely to attribute God as a cause of positive than negative occurrences in the lives of other people. The present study makes a novel contribution by showing that the tendency to view 
God as causally responsible for positive occurrences was marginally increased when mortality was salient. The present findings also support the construct validity of the Defensive Theology Scale [31]. Higher scores on the DTS were associated with viewing God as a more likely cause for all occurrences depicted in the vignettes. People who use their religion to ward off existential anxiety may be more likely to evoke God as directly involved in the events of the world regardless of the impact or valence of the consequences. In contrast to previous evidence that DTS moderated the effects of mortality salience on worldview defense, no relation between DTS and the effects of mortality salience on attributions to God was observed in the current study. Perhaps this reflects a ceiling effect, because those high on DTS viewed God as a very likely cause for all occurrences leaving little room for the death prime to increase the strength of these attributions.

Whereas, the mortality salience manipulation significantly reduced attributions to luck or chance for life-altering occurrences and marginally increased attributions to God for positive occurrences, it had no effect on attributions to the people affected or the actions of other people. This pattern was not surprising given that the vignettes used in the current study were selected because they were occurrences, in which the outcomes were not obviously related to the actions of the people involved. Previous studies have shown that mortality salience increased attributions of blame to other people in order to maintain a belief in a just world $[19,34]$. The current study differs from these previous studies in the feasibility with which the persons affected could reasonably be held accountable for what happened to them and in the degree to which participants could make alternative attributions that would protect their anxiety buffering assumptions about the world. People may not need to blame the victims for the negative life events that afflict them if they can alternatively maintain their assumptive worldview by perceiving the events as happening for some purpose.

It is interesting to note that the tendency for mortality salience to reduce attributions to luck or chance did not vary with individual differences in PNS. This finding adds to the discrepancy in the literature about the role PNS plays in moderating responses to reminders of death. The effect of mortality salience on preferences for meaningful and simple structures of the social world has been shown to be limited only to those high on PNS [33, 34]. In contrast, Davis et al. [20] found that PNS did not moderate the effect of mortality salience on teleological beliefs about the natural world. Davis et al., concluded that the need to perceive telos and the need for simple structure might be separate anxiety buffering aspects of cultural worldview. The results of the present study are consistent with the position of Davis et al.

\section{GENERAL DISCUSSION}

The results of the two studies reported here offer preliminary evidence in support of the terror management function of believing everything happens for a reason. The current findings add to the previous body of literature documenting how mortality salience can influence attribtuional processes $[17-19,34]$ and extend previous research on the terror management function of perceived purpose [20]. We argue that the results of the present paper should be taken as evidence in further support of the claim by Davis et al. [20] that perceived telos or purpose is an important assumption influencing human perceptions of the world. We agree with Davis et al. that facilitating perceived purpose is an important function of cultural worldview that along with describing the means for literal and symbolic immortality and setting the standards for self-esteem helps to ameliorate existential anxiety. It is difficult to view existence in general as meaningful and one's personal life as valuable without also being certain that there is a purpose to all events. Believing that humans are a more or less random product of an amoral evolutionary process makes it difficult to deny our similarity to other animals and our shared destiny doomed to the same corporeal fate. Believing that we are powerless against the chaotic forces of an indifferent universe is not conducive to maintaining psychological equanimity.

However, the results of the present studies are limited and the validity of the above claims must be further evaluated based on future research. The present research examined people's reactions to a limited number of hypothetical events affecting the lives of other people. It remains to be seen whether existential threat would motivate increased perceptions of purpose behind real life events or increase the belief that everything happens for a reason in reference to people's autobiographical memories. When thoughts of death are salient, people should be more likely to interpret their previous failures and sufferings as purposeful. Consistent with this idea, parents of children with terminal illnesses frequently mentioned their belief that everything happens for a reason as a source of comfort in difficult times [35].

The suffering of the innocent and the misfortune of those we care about may be threatening to the anxiety-buffering aspects of our cultural worldview unless they can be perceived as purposeful. However, when the guilty suffer or when misfortune befalls out-group rivals, existential anxiety may be quelled as our confidence in our cultural worldview is bolstered. Previous research has shown that when Christian participants read about the death of Muslims in an airplane crash, it negated the otherwise observed increase in death thought accessibility caused by a worldview threat manipulation describing the Muslim control over the city of Nazareth [36]. Other research has documented that schadenfreude, taking pleasure in the misfortunes of others, is increased when people are responsible for their plight [37]. Consequently, a fruitful avenue for future research would be to examine whether mortality salience increases feelings of schadenfreude when bad things happen to out-group members or those who violated cultural standards of moral behavior.

Observing the suffering of others might threaten or bolster the anxiety-buffering capacity of cultural worldview depending on the deservedness and group membership of those afflicted. However, mitigating existential anxiety in response to personal or observed misfortune would depend on the ability to perceive telos or purpose behind the events. The assumption that everything that happens occurs according to the beneficent design of an intentional universe is not amenable to scientific analyses because it is nonfalsifiable. Nonetheless, people may be strongly motivated to embrace 
such teleological thinking about the natural and social world in order to facilitate psychological defenses against existential terror.

\section{APPENDIX}

\section{Vignettes Used in Study 1 and Study 2.}

\section{Positive Not Life-altering}

The Taylors recently bought and moved into a house in the country. They discovered that the property was situated over a vein of rare minerals valuable for certain industrial processes. The mineral deposits were not large, but did yield enough for the Taylors to buy a new car.

\section{Negative Not Life-altering}

Tim's company requires all its employees to have a medical exam every two years. Last year it was discovered that Tim had a small growth on his neck. The growth was painful to remove and left an ugly scar.

\section{Positive Life-altering}

Carol had to work late one evening and missed the train she usually took home. She was able to catch a later train, and as she got on she ran into the woman who had been her best childhood friend. Carol felt an immediate rapport with her former chum, and she renewed their friendship for the rest of their lives.

\section{Negative Life-Altering}

Sam owned a small business and made a moderate living. One day, Sam received an urgent letter from his bank. The letter informed him that his loan had been called in for immediate payment of $\$ 40,000$ because of the fluctuating economy.

\section{CONFLICT OF INTEREST}

The authors confirm that this article content has no conflicts of interest.

\section{ACKNOWLEDGEMENTS}

"The authors would like to thank Sara Beth Horton and Jordan Carson for their assistance with data collection and entry."

\section{REFERENCES}

[1] Frankl VE. Man's search for meaning: an introduction to logotherapy. New York: Washington Square Press 1963.

[2] Baumeister RF. The cultural animal: human nature, meaning, and social life. New York: Oxford University Press 2005.

[3] Heine SJ, Proulx T, Vohs, KD. The meaning maintenance model: On the coherence of social motivations. Pers Soc Psychol Rev 2006; 10: 88-110.

[4] Kelly HH. The process of causal attributions. Am Psychol 1973; 28: $107-28$.

[5] Fiske ST, Taylor SE. Social cognition. New York: McGraw-Hill 1991.

[6] Kunda Z. The case for motivated reasoning. Psychol Bull 1990; 108: 480-98.

[7] Lerner MJ. Just world research and the attribtuional process: Looking back and ahead. Psychol Bull 1978; 85: 1030-51.

[8] Janoff-Bulman R. Shattered assumptions: Towards a new psychology of trauma. New York: Free Press 1992.
[9] Solomon S, Greenberg J, Pyszczynski T. Terror management theory of self-esteem. In: Snyder CR, Forsyth D, Eds. Handbook of social and clinical psychology: The health perspective. Oxford: Pergamon Press 1991; pp. 21-40.

[10] Greenberg J, Porteus J, Simon L, Pyszczynski T, Solomon S. Evidence of a terror management function of cultural icons: The effects of mortality salience on the inappropriate use of cherished symbols. Pers Soc Psychol Bull 1995; 21: 1221-8.

[11] Arndt J, Greenberg J, Pyszczynski T, Solomon S. Subliminal exposure to death-related stimuli increases defense of the cultural worldview. Psychol Sci 1997; 8: 379-85.

[12] Greenberg J, Pyszczynski T, Solomon S, et al. Evidence for terror management theory II: the effects of mortality salience on reactions to those who threaten or bolster the cultural worldview. J Pers Soc Psychol 1990; 58: 308-18.

[13] Schimel J, Hayes J, Williams T, Jahrig J. Is death really the worm at the core? Converging evidence that worldview threat increases death thought accessibility. J Pers Soc Psychol 2007; 92: 789-803.

[14] Greenberg J, Simon L, Harmon-Jones E, Solomon S, Pyszczynski T, Lyon D. Testing alternative explanations for mortality salience effects: terror management, value accessibility, or worrisome thoughts? Eur J Soc Psychol 1995; 25: 417-33.

[15] Greenberg J, Martens A, Jonas E, Eisenstadt D, Pyszczynski T, Solomon S. Psychological defense in anticipation of anxiety: eliminating the potential for anxiety eliminates the effects of mortality salience on worldview defense. Psychol Sci 2003; 14: 516-9.

[16] Dechesne M, Pyszczynski T, Arndt J, et al. Literal and symbolic immortality: the effects of evidence of literal immortality on selfesteem strivings in response to mortality salience. J Pers Soc Psychol 2003; 84: 722-37.

[17] Mikulincer M, Florian V. The effects of mortality salience on selfserving attributions - evidence for the function of self-esteem as a terror management mechanism. Basic Appl Soc Psych 2002; 24: 261-71.

[18] Nelson LJ, Moore DL, Olivetti J, Scott T. General and personal mortality salience and nationalistic bias. Pers Soc Psychol Bull 1997; 23: 884-92.

[19] Hirschberger G. Terror management and attributions of blame to innocent victims: Reconciling compassionate and defensive responses. J Pers Soc Psychol 2006; 91: 832-44.

[20] Davis W E, Juhl J, Routledge C. Death and design: the terror management function of teleological beliefs. Motiv Emot 2011; 35: 98104.

[21] American Psychological Association. Ethical principles of psychologists and code of conduct. Am Psychol 2002; 57: 1060-73.

[22] Gosling S, Rentfrow P, Swann WB Jr. A very brief measure of the big five personality domains. J Res Pers 2003; 37: 504-28.

[23] Hirschberger G, Ein-Dor T. Does a candy a day keep the death thoughts away? The terror management function of eating. Basic Appl Soc Psych 2005; 27: 179-86.

[24] Watson D, Clark LE, Tellegen A. Development and validation of brief measures of positive and negative affect: the PANAS scales. J Pers Soc Psychol 1988; 54: 1063-70.

[25] Lyall H, Thorsteinsson E. Attitudes to the Iraq war and mandatory detention seekers: Associations with authoritarianism, social dominance, and mortality salience. Aust J Psychol 2007; 59: 70-7.

[26] Goldberg LR, Johnson JA, Eber HW, et al. The International Personality Item Pool and the future of public-domain personality measures. J Res Pers 2006; 40: 84-96.

[27] Pyszczynski T, Greenberg J, Solomon S. Why do we need what we need? A terror management perspective on the roots of human social motivation. Psychol Inq 1997; 8: 1-20.

[28] Lupfer MB, Tolliver D, Jackson M. Explaining life- altering occurrences: A test of the 'God-of-the-gaps' hypothesis. J Sci Study Relig 1996; 35: 379-91.

[29] Keen S. Beyond psychology: a conversation with Ernest Becker. In: Liechty D, Ed. The Ernest Becker reader, The Ernest Becker Foundation USA: Washington Press 2005; pp. 219-29.

[30] Beck R. The function of religious belief: defensive versus existential religion. J Psychol Christ 2004; 23: 208-18.

[31] Beck R. Defensive versus existential religion: Is religious defensiveness predictive of worldview defense? J Psychol Theol 2006; 34: $143-53$.

[32] Neuberg SL, Newsome JT. Personal need for structure: Individual differences in the desire for simple structure. J Pers Soc Psychol 1993; 65: 113-31. 
[33] Landau MJ, Greenberg J, Solomon S, Pyszczynski T, Martens A. Windows into nothingness: Terror management, meaninglessness, and negative reactions to modern art. J Pers Soc Psychol 2006; 90: 879-92.

[34] Landau MJ, Johns M, Greenberg J, et al. A function of form: terror management and structuring the social world. J Pers Soc Psychol 2004; 87: 190-210.

[35] Hexen KR, Mollen CJ, Carroll K, Lanctot DA, Feudtner C. How parents of children receiving pediatric palliative care use religion, spirituality, or life philosophy in tough times. J Palliat Med 2011; 14: 39-55.

[36] Hayes J, Schimel J, Williams TJ. Fighting death with death: the buffering effects of learning that worldview violators have died. Psychol Sci 2008; 19: 501-7.

[37] van Dijk WW, Goslinga S, Ouwerkerk JW. Impact of responsibility for a misfortune on Schadenfreude and sympathy: Further evidence. J Soc Psychol 2008; 148: 631-6.

(C) Bassett and Going; Licensee Bentham Open.

This is an open access article licensed under the terms of the Creative Commons Attribution Non-Commercial License (http://creativecommons.org/licenses/ by-nc/3.0/) which permits unrestricted, non-commercial use, distribution and reproduction in any medium, provided the work is properly cited. 